The Division of Natural Sciences will also play a part in a number of schemes supported by the Organisation, but having a wide range and affecting other branches of knowledge. These include methods of dealing with rehabilitation in war-devastated countries, exchange of personnel between countries, passage of books across frontiers, documentation, use of mass media for the spread of information, etc. ; as in the case of libraries and museums, men of science are directly concerned in these projects, but only as part of a much wider group of interested people. The same applies to certain aspects of education, which provide the main body of the activities of the Organisation, and call for a separate report in itself.

With regard to the future position of science in the United Nations Educational, Scientific and Cultural Organisation, one fact must be borne in mind. The natural sciences were well organised at the start along intermational lines, while certain other subjects such as the humanities and the social sciences were not. As they fall into line-and the Division for Philosophy and the Humanities has already asked the Organisation to organise a central council along the lines of the International Council of Stientific Unions-they will find useful ways of spending money and will make their appeal to the Organisation for grants. Unless the income of the Organisation rises with its increased opportunities and responsibilities, the grants to science will be maintained at their present level only with difficulty.

In elosing this account, tribute must be paid to the Mexican Government for its gracious welcome and generous hospitality ; the Lebanese Government has been set a hard task for this year's conference at Beirut. This will be the last conference at which Dr. Julian Huxley will hold office as director-general. Dr. Needham retires from the post of head of the Natural Sciences Division this spring. Both of them have placed the scientific men of the world under a debt of obligation by the way they have initiated the scientific section of an organisation which has great possibilities for the future of the civilized world.

F. J. M. S.

\section{THE EARTH'S SURFACE MAGNETIC FIELD AND ITS SECULAR CHANGE}

\section{By Prof. SYDNEY CHAPMAN, F.R.S.}

$\mathrm{T}$

HE Department of Terrestrial Magnetism of the Carnegie Institution of Washington renders a signal service to science by the publication of the important volume entitled 'Description of the Earth's Main Magnetic Field and its Secular Change, 19051945 ". In a sense this represents the attainment (for the time) of one primary objective urged by the first director of the Department, the late L. A. Bauer, upon Andrew Carnegie, in the negotiations which led in 1904 to the institution of the Department. The volume has been prepared almost entirely under the control of the second director, J. A. Fleming, who from early days was Bauer's right-hand man in the development of the Department. The third director is to be congratulated on being able to issue so great a contribution to the science for the furtherance of which his Department was founded.

Bauer set himself with immense zeal to the task of promoting a world magnetic survey more complete than any previously attempted. As most of the earth's surface is water, the chief need was to survey the oceans. Bauer acquired a sailing vessel, the Galilee, for his Department, and adapted it (adding auxiliary engines) for magnetic survey work, on which it made three cruises. A non-magnetic vessel, the Carnegie, was then specially constructed, which made seven great survey cruises before it was over. taken by the disaster of destruction by fire in the harbour of Apia, Samoa, in 1929. These cruises form the main basis of our knowledge of the earth's surface magnetic field to-day, though supplemented by information provided by the land magnetic surveys undertaken by the principal civilized States in their own or dependent territories, and by the work of many polar and other expeditions.

Since 1929 our knowledge of the earth's magnetism has been slowly worsening. The outbreak of war halted the completion and equipment of the Royal Research Ship Research, a non-magnetic vessel built by the British Admiralty to resume the ocean magnetic survey work so well executed by the Carnegie during two decades. The fate of the Research is at present in doubt, but it may be hoped that the ship will soon begin her work and help to renew our current knowledge of the earth's ever-changing magnetic state.

Although Bauer intended to make a thorough theoretical study of the magnetic data obtained by his survey ships and by the land magnetic expeditions he organised or aided, along with all other available data, he actually made only slight progress in this work. But with generous wisdom he made his data quickly available for use in the construction of magnetic charts by the principal national agencies responsible for producing such charts. In particular, the early work of the Galilee and Carnegie formed the basis of the Admiralty charts when their preparation was transferred in 1917 to the Royal Observatory, Greenwich.

The supervision of this work by the then Astronomer Royal, the late Sir Frank Dyson, enhanced his interest in geomagnetism and led him, with $H$. Furner, to make an excellent spherical harmonic analysis of the earth's field for the epoch 1922-the only thorough analysis made during a considerable period extending before and after 1922 .

The subsequent further accumulation of magnetic data enhanced the need for further study of the worldwide distribution and secular change of the field. A valuable beginning of this work was made in 1930 by $H$. W. Fisk (of the Department of Terrestrial Magnetism, Carnegie Institution), by his isoporic charts showing for each magnetic element the lines (isopors) of equal rate of secular change. The Department's plans for a more comprehensive treatment of this century's store of magnetic data first began to mature rapidly when, during the War, the work became the subject of a Government contract under the United States Naval Department. It was entrusted to a team of members of the staff of the Department of Terrestrial Magnetism, under the able leadership of E. H. Vestine, and has been executed thoroughly and successfully. The volume now under notice is the first fruits, and is to be followed by others giving a new spherical harmonic analysis of the field, and other developments.

The main contents of the volume indicate (i) the state of the earth's surface magnetic field for the epoch $1945 \cdot 0$, and (ii) the rate of change of the field at each of the four epochs $1912 \cdot 5,1922 \cdot 5,1932 \cdot 5$ and $1942 \cdot 5$. The field can be specified at any point by 


\section{No. 4083 January 31, $1948 \quad$ N A T U R E}

three elements, such as $D$ the magnetic declination, $H$ the horizontal magnetic intensity, and $Z$ the vertical intensity; but other specifications are equally valid, involving one or more of these three elements, together with a choice from the further four elements, $X$ and $Y$ the north and east horizontal components, $F$ the total intensity, and $I$ the magnetic inclination or dip. All these elements are represented in this volume (though not all to an equal extent) by charts, tables and graphs. They are based on more than 100,000 individual observations, relating to nearly 10,000 stations for $D$ and 5,000 stations for the other elements.

There are sixty-three isomagnetic charts for $1945 \cdot 0$, namely, fifteen large-scale sectional diagrams on Mercator's projection, with two polar charts (northern and southern) for the elements $D, H$ and $Z$, and three charts (one Mercator, covering the middle belt between latitudes $73^{\circ} \mathrm{S}$. and $84^{\circ} \mathrm{N}$., and two polar charts, north and south) for each of the other four elements.

The isoporic charts number eighty-four, namely, three each (two polar and one for the belt $73^{\circ} \mathrm{S}$. to $84^{\circ}$ W.) for each of the seven elements for each of the four epochs.

Only the middle-belt isomagnetic charts (for $X, Y$, $F$ and $I$ ) and the middle-belt isoporic charts show the background of geographical outlines.

The unusually large scale of the isomagnetic $1945 \cdot 0$ charts for $D, H$ and $Z$ enables smaller anomalies to be shown than is usual on magnetic maps, at least over the oceans. But Vestine explicitly disavows any claim that the charts represent an accurate description of the field, because there are many regions which have never been magnetically surveyed, across which uncertain interpolations had to be made.

Values for 1945.0 of each of the seven elements, scaled from the charts at $5^{\circ}$ intervals of latitude and longitude, and of their rates of secular change at each of the four epochs, scaled from the isoporic charts at $10^{\circ}$ intervals of latitude and longitude, are given in tables, part of which are separately published ${ }^{2}$.

The volume also includes 214 graphs showing the time variation of each element (separately for $D, H$ and $I$, and in combination for $X, Y, Z$ and $F$ ) for a hundred magnetic observatories, and a sample of eleven repeat stations (out of about two thousand for which such graphs were prepared in the course of the work). The positions of the observatories and of the survey and repeat stations are shown on supplementary charts.

This volume is unique in geomagnetic literature not only for the extent of the underlying data and the fullness of the reduction and representation of the data ; it is the first to describe at all adequatelv the nature of the processes of reduction and representation, with examples of the actual working sheets of computations for a typical observing station. A useful improvement in the work has also been made by rendering the $X$ and $Y$ charts, and the $D$ and $H$ charts (both isomagnetic and isoporic), mutually consistent on the hypothesis of negligible electric currents crossing the earth's surface ; and also by the use of simple analytic considerations on the form of the isomagnetic and isoporic lines near dip poles.

The volume is a worthy embodiment and memorial of the first quarter-century of the observing work of the Department of Terrestrial Magnetism; may this work be emulated and surpassed during the remainder of this twentieth century. The development of methods of aerial magnetic survey seems to hold much promise for the future, though meanwhile welltried methods should not be neglected.

1 Carnegie Institution of Washington: Department of Terrestrial
Magnetism. Publication $578:$ Description of the Earth' Main
Magnetic Field and its Secular Change, 1905-1945. By E. H.
Vestine, Lucile Laporte, Caroline Cooper, Isabelle Iange and
W. C. Hendrix. Pp. v+532. (Washington, D.C. : Carnegie
Institution, 1947.) 2.50 dollars. (W.
${ }^{2}$ Carnegie Institution of Washington: Department of Terrestrial
Magnetism. Final Values of Elements of the Geomagnetic Field
at 5-Degree Intervals of Latitude and Longitude, Epoch 1945.
By L. Laporte, C. Cooper, I. Lange, W. C. Hendrix and E. H.
Vestine. Pp. 73. (Washington, D.C.: Carnegie Institution,
1946.) n.p.

\section{OBITUARY}

\section{Prof. Ludwig Becker}

Prof. Ludwig Wilhelm Emil Ernst Becker, for forty-two years occupant of the regius chair of astronomy in the University of Glasgow, died at Merano in Italy on November 11, 1947. Becker was borm at Wesel in Germany in 1860 and educated at the University of Bonn where, in due course, he took his Ph.D. degree. In 1885, after two years as an assistant in the Berlin Observatory, he was recommended to the Earl of Crawford and Balcarres, who owned a large private observatory at Dunecht, near Aberdeen, in professional charge, at the time, of Dr. R. Copeland. In the autumn of 1888 Lord Crawford presented the whole of his magnificent equipment, including his astronomical library of 15,000 volumes, to the Lords Commissioners of the Treasury for a new Royal Observatory. A site on Blackford Hill in Edinburgh was selected in 1889 ; Becker was included on the staff, with Copeland as Astronomer Royal. Four years later, Becker was appointed to the regius professorship of astronomy at Glasgow, occupying the chair until his retirement in 1935. The University Observatory half a century ago was well equipped for contemporary needs, and in his earlier years he extended considerably its instrumental resources.

Becker was an inspiring teacher. His 'honours. lectures' were mainly on celestial mechanics, of which he was a master. His scientific work covered a wide variety of subjects, of which the following may be mentioned: his investigation on the distribution of blue-violet light in the solar corona at the eclipse of August 30, 1905, in Tunisia ; a long and careful investigation on the constant of aberration under. taken with the Glasgow transit circle; a capturehypothesis relating to binary stars, in which he showed how such a system could capture a third star, losing in the process one of its own components, and how the hypothesis could account for the high eccentricities of binary star orbits (it may be added that this idea of capture has recently been adopted by Lyttleton in his earlier attempts to explain the formation of the planetary system); descriptions of various instrumental improvements such as a motor-micrometer for the transit circle and a new 'artificial horizon' for sextants.

Although Becker had become a naturalized British citizen before his appointment to Glasgow, this fact failed to save him from embarrassment and unmerited suspicion during the First World War ; local public opinion forced his temporary retirement to Aviemore in the Highlands, where he lived in seclusion until the end of hostilities. Becker was one of the gentlest of men, modest and retiring in disposition and, whatever the outside world thought, respected and esteemed by his students both for his learning and his kindly qualities. $\quad$ W. M. SMART 